\title{
ANTROPOLOGI PENDIDIKAN DAN MENGAPLIKASIKAN DALAM PEMBANGUNAN INDONESIA
}

\author{
Titis Muthiana Taqwim \\ Email: 2010128220023@ulm.ac.id \\ Program Studi Pendidikan IPS Fakultas Keguruan dan Ilmu Pendidikan \\ Universitas Lambung Mangkurat \\ Banjarmasin
}

\begin{abstract}
Abstrak
Ilmu antropologi ialah disiplin kajian ilmu yang tentang proses transformasi kehidupan manusia dengan berbagai keanekaragamannya,baik itu pola kehidupan ditinjau dari sudut pandang pola perilaku, kebudayaan dan lain sebagainya .Tujuan penelitian ini memperkenalkan bahwa, Antropologi sebagai ilmu terapan yang dapat berperan dalam membangun bangsa dan negara, mempelajari cara-cara hidup manusia,dan kebiasaan terhadap lingkungan sekitarnya dalam mengatur hubungan antar sesama manusia.
\end{abstract}

\section{PENDAHULUAN}

Jika kita cermati bahwasannya masyarakat Indonesia terdiri dari keberagaman latar belakang kebudayaan daerah, suku, adat istiadat serta bahasa yang berbeda, sehingga pendidikan tidak dapat dipisahkan dari latar yang beragam.Sebagimana yang kita ketahui Kegiatan proses pembelajaran dalam pendidikan tidak mungkin dan tidak dapat dilepaskan dari latar belakang yang melingkupinya.

Menurut (Jacob,2006) menyatakan bahwa individu selalu menantang dirinya sendiri dalam hal berpikir,mencari,mengubah dan melahirkan kebudayaan untuk meningkatkan peradabannya dalam menyelesaikan masalah disekitar hidupnya.Dalam pendidikan antropologi ini juga terdapat nilai-nilai yang turut membawa peserta didik untuk mengerti tentang pola di masyarakat dan dapat turun tangan berpartisipasi dalam pembangunan di Indonesia.Menurut (Tilaar,2002) beliau mengatakan,bahwa pendidikan dan kebudayaan itu berproses secara berubah-ubah untuk mengatur tatanan kehidupan bermasyarakat, adanya proses pemanusiaan dan tujuan tentang kehidupan.

Dalam pandangan antropologi dalam pembangunan Indonesia itu diarahkan untuk membangun masyarakat yang lebih baik dan menuju peradaban selanjutnya.Tentunya, dalam hal ini bahwa masyarkat menjadi subjek dan objek utama dalam pembangunan tersebut.Antopologi juga didalamnya terdapat kebudayaan yang berfungsi sebagai nilai tambah dalam proses pembangunan agar masyarakat sesuai dengan tatanan. 


\section{Kata Kunci : Antropologi,Pendidikan,Pembangunan Indonesia. METODE PENELITIAN}

Dalam penulisan artikel ini saya menggunkan metode studi kajian literatur.Penulis menggunkankan jurnal-jurnal dan buku yang relevan.Kemudian, Bahan yang sudah dikumpulkan dan di pilih. Setelah itu ,dibuatlah beberapa serangkaian penulisan secara fakta dan membentuk menjadi sebuah penulisan artikel.

\section{DASAR ANTROPOLOGI PENDIDIKAN}

Secara Secara harfiah dari bahasa Yunani kata antropos berarti "manusia" dan logos berarti "studi" jadi antropologi adalah suatu disiplin berdasarkan rasa ingin mempelajari tentang bagaimana cara suatu individu memahami tnatang manusia dengan berbagai falsafah dan tata cara kehidupannya.Sehingga ilmu antropologi dapat disederhanakan sebagai sebuah kajian ilmu yang mempelajari tentang proses perubahan kehidupan manusia dengan berbagai keanekaragamannya, baik itu pola antropologi pendidikan yaitu teori-teori serta metode-metode tentang pengetahuan yang berhubungan dengan kebutuhan manusia dan masyarakat sehingga meningkatkan wawasan ilmu pengetahuan dalam dunia pendidikan. Ada dua cabang utama dalam aspek kajian ilmu antropologi, yaitu antropologi fisik dan antropologi budaya.

\section{a.Antropologi Fisik}

Antropologi fisik ini mengkaji perkembangan fisik atau perilaku manusia,yaitu cara manusia beradaptasi pada lingkungannya. Dalam perkembangan manusia ditinjau secara biologis menurut evolusinya dengan berbagai keistimewaan dan potensi yang telah ada dalam dirinya.Para ahli antropolog pada meninjau kera sebagai dasar asal mula leluhur manusia,karena memiliki banyak persamaan ciri-ciri pertumbuhan dengan manusia pada umumnya, mereka mencoba menganalisis secara mendalam terhadapfosil-fosil primata untuk mengetahui bagaimana dan kapankah sejarah asal perkembangan manusia hingga menjadi seperti sekarang.

Manusia beusaha mengembangkan kemampuan,keterampilan,dan pengetahuan yang dimiliki dalam mengelola sumber daya alamdisekelilingnya. Dan juga itu, manusia mengatur sebuah proses hubungan interaksi, timbal balik dalam suatu pola perilaku bermasyarakat. Pola aturan perilaku bermasyarakat akan menjadi panutan dari masyarakat sekitar untuk berinteraksi dengan masyarakat lain. Pola aturan perilaku ini disebut norma atau nilai-nilai yang menjadi dasar dari pola aturan perilaku yang dianut oleh masyarakat tersebut. Ketiga wujud kebudayaan diatas yang berupa sistem nilai, pola aturan, dan perilaku tersebut tidak dapat dipisah-pisahkan di dalam kehidupan kita. 


\section{b.Antropologi Budaya}

Para antropolog mengatakan istilah "kebudayaan" pada umumnya mencakup bagaimana seseorang dalam berpikir dan bertindak dalam lingkungan sosialnya dalam suatu kelompok masyarakat secara khusus.Dalam antropologi aspek kebudayaan terdiri dari keberagaman bahasa, niali dan norma, adat istiadat dan tradisi keagamaan.Seorang arkeolog mengatakan dari hasil pengamatannya bahwa kemunculan suatu peradaban suatu wilayah tentang perubahan sosial masyarkat disuatu tempat sehingga perubahan dimasa lalu dijadikan sebagai sumber acuan untuk dapat memahami perkembangan sosial budaya masyarkat di masa yang selanjutnya.Dan para pakar arkeolog berusaha dalam mengumpulkan data dengan berupa keping-kepingan sisa zaman dulu dan cara tersebut merupakan dasar sebagai seorang pakar arkeolog untuk mengetahui atau membuat suatu tesis tentang kebiasaan,pola perilaku serta kebudayaan masyarakat di zaman yang dapat menjadi acuan di periode selanjutnya.

\section{Pendidikan dan Antropologi}

Pendidikan secara luasnya yaitu menyangkut usaha suatu individu untuk mengembangkan dirinya baik rohani maupun jasmani dengan melalui proses pendewasaan melalui pembelajaran.Dalam Undang-undang No.20 tahun 2003 tentang sistem pendidikann pasal 3 yaitu tentang tujuan pendidikan yakni mengembangkan potensi peserta didik agar menjadi manusia yang beriman dan bertaqwa kepaa Tuhan Yang Maha Esa, berakhlak mulia,sehat,berilmu,cakap,kreatif,mandiri serta menjadi warga negara yang demokratis serta bertanggung jawab.

Secara sistematik,Antropologi pendidikan mengkaji mengenai praktik pendidikan dalam sudut pandang kebudayaan.Kebudayaan tersebut yang sebagai warisan kepada anak bangsa dalam sebuah kumpulan masyrakat sebagai bekal pengalaman.Para arkeolog dan pendidikan bekerjasama dalam menyebar luaskan kebudayaan dalam bagian-bagian pendidikan dan berupanya melestarikan hasil-hasil kebudayaan tersebut.Sifat kajian dalam antopologi pendidikan menekankan tantang perbedaan suatu kelompok manusia yang meliputi persepektif karakteristik budaya ,perilaku,maupun norma tradisi,bahasa,falsafah hidup yang dianut masyarakat,dan penciptaan pada teori-teori pendidikan.

\section{Mengaplikasikan Antropologi dalam Pembangunan Indonesia}

Antropologi di Indonesia telah berkembang dalam beberapa tahun terakhir ini,tetapi bagaimana peran disiplin ilmu antropologi dalam pembangunan Indonesia.Untuk mengaplikasikan ilmu antropologi dengan pembangunan di Indonesia,Antopologi terdapat hubungan dan keterkaitan dengan disiplin ilmu seperti ilmu sosiologi dan ilmu politik.Antopologi dalam pembangunan nasional ditinjau dari tiga unsur utama yaitu, peran antropolog di Indonesia,pengembangan sistem pendidikan antropologi di Indonesia dan pembangunan Indonesia.Para antopolog wajib memperhatikan lim dasar yang menjadi aspek dasar kebijakan pembangunan di Indonesia yaitu sebagai berikut : Pancasila dan UUD 1946,GBHN,PELITA dan kebijakan-kebijakan departemen (Marzali,2000). 
Dalam menyusun sebuah program suatu kebijakan negara terdpat ciri-ciri umum masyarakat dan kebudayaan dari suatu kelompok masyarakat yang harus ditinjau terlebih dahulu oleh karena itu, para antropolog harus menguasai konsep dasar dalam teori pembangunan di indonesia agar dapat mengaplikasikannya.Mengaplikasikan antropologi pendidikan dalam pembelajaran peserta didik, maka antropologi untuk pembangunan Indonesia mampu menyiapkan peserta didik yang berdaya saing secara mendunia.

\section{SIMPULAN}

Antropologi Pendidikan memahami tentang bagaimana suatu individu melakukan proses praktik pendidikan yang ditinju dari perspektif menurut sudut pandang kebudayaan masyarakat.Dengan adanya antropologi pendidikan dapat memperhatikan latar kebudayaan yang berbeda disetiap peserta didik sehingga dapat terwujudnya kegiatan belajar dan mengajar yang berwawasan kearifan.Dengan begitu merupakan salah satu langkah bijak dalam memperkenalkan faktor kebudayaan dalam perkembangan kecerdasan peserta didik.

Dindonesia perkembangan di masyarakat setiap wilayah masing-masing suku bangsa memiliki kebudayaan yang bebeda-beda dengan pengalaman individu yang berbeda.Tingkat kemajuan masyarakat di setiap wilayah masing-masing suku bangsa Indonesia dipengaruhi oleh pengetahuandan pegalaman masyarakat itu. Kemudian tingkat kebutuhan,pola pikir serta ctata cara bertahan hidup masyarakat dipengaruhi oleh perkembangan dan kemajuan kebudayaan masyarakat disetiap wilayahnya masing-masing. Dengan adanya antropologi pendidikan dan mengaplikasikannya dalam kehidupan dapat membantu mewariskan sistem nilai-nilai kebudayaan. 


\section{REFERENSI}

Abbas, E. W. (1996). Bab Antropologi. Banjarmasin: EWA Book Company.

Abbas, E. W. (2015). Pendidikan IPS Berbasis Kearifan Lokal. WAHANA Jaya Abadi.

Abbas, E. W. (2016). Etnopedagogi: Pendidikan Berbasis Kearifan Lokal.

Abbas, E. W. (2020). Metode Guru Sekumpul Sebagai Inovasi Pembelajaran IPS Berbasis Budaya Lokal.

Amin, S., \& Murtaufiq, S. (2017). MENGAMATI INDONESIANIS: DARI ANTROPOLOGI BUDAYA, POLITIK KOLONIAL HINGGA HEGEMONI DAN PENGENDALIAN WACANA MODERN. Mozaic: Islam Nusantara, 3(1), 31-64.

Indriyawati, E. (2009). Antropologi. Jakarta: Pusat Perbukuan Departemen Pendidikan Nasional.

Kahar, S., Barus, M. I., \& Wijaya, C. (2019). ANTHROPOS: Jurnal Antropologi Sosial dan Budaya. Anthropos, 4(2), 170-178.

Mutiani, M. (2018). Literasi Budaya Lokal Sebagai Wahana Edukasi Di Era Milenial.

Nugroho, Y. S. (2021). Tugas Antropologi Budaya.

Rasimin, R. (2018). ANTROPOLOGI PENDIDIKAN: PENDEKATAN SOSIAL BUDAYA.

Ruswanto, W. (1997). Ruang Lingkup Ilmu Antropologi. Ruang Lingkup Antropologi.

Sarbaini, S., ABBAS, E. W., Wahyu, W., \& SOFYAN, A. (2020). PENDIDIKAN KARAKTER.

Satria, R., Hanum, N. A., Shahbana, E. B., Supriyanto, A., \& Ulfatin, N. (2020). LANDASAN ANTROPOLOGI PENDIDIKAN DAN IMPLEMENTASINYA DALAM PEMBANGUNAN Indonesia. Indonesian Journal of Social Science Education (IJSSE), 2(1), 49-65.

Syaharuddin, S., \& Mutiani, M. (2020). Strategi Pembelajaran IPS: Konsep dan Aplikasi.

Syaharuddin, S. (2020). Nilai-Nilai Sejarah Lokal (Banjar) dalam Pembelajaran IPS (Studi pada Sejarah Lokal Kalimantan Selatan Periode Perang Banjar, 1859-1906). 